\section{Dr Cavalli's wild ride}

\author{
A Genetic and Cultural Odyssey: The Life and Work of \\ L Luca Cavalli-Sforza \\ Linda Stone and Paul F Lurquin \\ Columbia University Press, New York, USA; 2005. 227pp. \\ Price £29.50, hardback. ISBN 0231133960.
}

Heredity (2007) 98, 243-244. doi:10.1038/sj.hdy.6800938

\section{Reviewed by JL Mountain}

One afternoon late in 1987, the year I began working with him, Luca Cavalli-Sforza called me into his office. Laid out on his desk was a pencil-drawn diagram consisting of two parts. On the left Cavalli-Sforza had redrawn a tree of relationships among human populations derived from genetic data. On the right he had summarized the relationships among languages spoken by each population. In great excitement Cavalli-Sforza pointed out the extent of the correspondence between the two sides of the diagram. With that diagram he sowed the seeds of a debate that continues today: to what extent do human genetic and linguistic patterns correspond, and how did any such correspondence arise?

How did it occur to Cavalli-Sforza to line up the two parts of the diagram side-by-side? And, having done so, how did he recognize that the joint pattern provided exciting, novel insights? In their new, authorized biography, Linda Stone and Paul Lurquin note that many people are astonished by Cavalli-Sforza's 'knack for grasping data and his insights into new avenues of research.' With their detailed description of CavalliSforza's works and discoveries, these authors provide readers with a window into the world of this extraordinarily successful, highly interdisciplinary scientist.

Stone, an anthropologist, and Lurquin, a geneticist, interviewed Cavalli-Sforza extensively while writing this book, which is highly ambitious for its length. Chapter 1 provides a brief overview of concepts in genetics and anthropology and an exposition of the goals of the authors. Subsequent chapters cover each of six overlapping time periods.

In Chapter 2, focusing on years 1943-1960, readers learn that a 13-year-old Cavalli (as these authors call him) embraced evolutionary theory despite his introduction to the theory by a critic teaching a religion class. In this chapter, we also learn of Cavalli's seminal role in the discovery of the nature of genetic exchange, or sex, among bacteria, through collaboration with Nobel Laureate Joshua Lederberg, among others. Indeed, one of the strengths of the book is the authors' recognition of the importance of Cavalli's many long-term collaborations.

Chapter 3, covering Cavalli's studies of human populations between 1952 and 1970, takes the reader on a 'wild ride' through a range of topics. The authors begin with a brief introduction to the field of genetics, subdivided into classical, molecular and population genetics. The reader then learns of Cavalli's role in demonstrating the importance of random genetic drift in generating human genetic diversity. This demonstration involved conducting, in the 1960s, the first computer simulation of the genetics of human populations. Chapter 3 also provides details of statistical methodology (such as Principal Component Analysis); a description of Cavalli's field trips to Africa to work with Pygmies and other populations; and Cavalli's early thoughts on cultural evolution. The authors next describe the beginnings of yet another fruitful long-term collaboration, with Sir Walter Bodmer, and then conclude the chapter with a discussion of student revolutions at European universities.

Chapters 4 and 5 cover the years 1970 through the present, with Chapter 4 focusing on Cavalli's study of human culture and Chapter 5 focusing on his inference of human prehistory. Chapter 4 opens with a discussion of Cavall's tripartite motivation for studying cultural evolution. His collaboration with Albert Ammerman on demic diffusion in Europe grew out of his observations of hunter gatherers and farmers in central Africa. Here, as elsewhere in the book, Cavalli is an advertisement for breadth of experience. This chapter also mentions Cavalli's 1970's debates with William Shockley regarding race. Then Stone and Lurquin describe Cavalli's initial collaboration with Marcus Feldman, which led to a rigorously developed theory of cultural evolution. The authors address the question of why that work has had little influence within cultural anthropology. In Chapter 5 the authors examine Cavalli's contributions to debates regarding topics in human prehistory, including the origins of modern humans, the peopling of the Americas, the origin and spread of Indo-European languages, and the correspondence between genetic and linguistic patterns of human diversity. To their credit, the authors are careful to note not only the parallels between genetic and linguistic evolution, but also the contrasts.

Chapter 6, covering 1984 to the present, outlines Cavalli's contribution, through the work of Peter Underhill and Peter Oefner, to current knowledge of human Y chromosome variation. This chapter, like others, includes a fair amount of scientific detail. Chapter 7, covering 1991 to the present, describes Cavalli's efforts to launch the Human Genome Diversity Project, and the ensuing controversies surrounding that project. In their final chapter, Stone and Lurquin examine Cavalli's legacy, arguing that if legacy is equivalent to controversy, then Cavalli leaves such a legacy.

Although the book proceeds somewhat chronologically, in general it is highly nonlinear, jumping from topic to topic within chapters. Readers may find the introductory chapter particularly challenging. One might argue that the organization parallels the non-linearity of Cavalli-Sforza's thought processes and indeed, his life. Another factor, however, is the authors' worthwhile goal of considering social aspects of the science. I suspect that any organization of this highly dimensional material, especially in a relatively short format, would have resulted in something of a 'wild ride' for the reader.

This book, written by a natural and a social scientist, focuses on one man's scientific contributions and their 
social context. The audience is likely to include scientists as well as non-scientists with an interest in science. Inevitably readers will find some sections overly simplistic and others overly technical. They will also find the authors to be relatively uncritical of their subject, and the prose awkward at times. However, Stone and Lurquin have captured Cavalli-Sforza's energy and spirit, and have successfully conveyed his broad impact on science and society. They also deserve credit for using many of Cavalli-Sforza's original articles as sources, and for bringing out the role of curiosity, and the opportunity for adventure, in science. Although undoubtedly not the last biography of Cavalli-Sforza, this book is likely to remain unique because of its collaborative nature. It is unlikely that any single person - geneticist, anthropologist or neither - could write a relatively accessible book with such attention to both the scientific and social dimensions of Cavalli-Sforza's life and work.

JL Mountain Departments of Anthropological Sciences and Genetics, Stanford University, Stanford, CA, USA E-mail: mountain@stanford.edu 